\title{
UNILATERAL MULTIFOCAL CHORIORETINOPATHY A CLUE TO HERPES ZOSTER OPHTHALMICUS
}

\author{
L. Satya Hareesh Reddy¹, Sulatha V. Bhandary2, Krishna Rao A33, Lavanya G. Rao ${ }^{4}$
}

1 Junior Resident, Department of Ophthalmology, Kasturba Medical College, Manipal.

${ }_{2}^{2}$ Additional Professor, Department of Ophthalmology, Kasturba Medical College, Manipal.

3 Professor and HOD, Department of Ophthalmology, Kasturba Medical College, Manipal.

4 Professor and HOD, Department of Ophthalmology, Srinivas Medical College, Mukka, Surathkal.

\section{ABSTRACT}

\section{BACKGROUND}

The presence of unilateral, multifocal, depigmented lesions in retina and choroid can be a late manifestation of Herpes Zoster Ophthalmicus (HZO). Though, these lesions have not been reported to cause visual impairment, they can cause diagnostic dilemma for the clinicians and financial burden on patient to undergo unnecessary investigations. This dilemma is due to fact that by the time these fundus lesions appear other ocular lesions of HZO may have healed and even forgotten by patients. Since, Herpes Zoster Chorioretinopathy (HZCR) is a rare entity (Only three reports available till date) reporting of such case will help clinician to be aware and suspect $\mathrm{HZO}$ as cause of chorioretinopathy thus avoid unnecessary investigations.

\section{FINDINGS}

A 50 years female presented with irritation in left eye. Examination revealed decreased corneal sensations and dry eye. Fundus showed multiple, healed, depigmented chorioretinal lesions. Optical coherence tomography showed increased back scattering from choroid. Fundus fluorescein angiography showed window defects. History suggested previous attack of HZO. On review, choroidal lesions remained same without visual impairment. Pathophysiology is occlusive vasculitis. A diagnosis of HZCR was made.

\section{CONCLUSION}

Hence in a case of unilateral multifocal chorioretinopathy, HZO as an aetiological possibility should be kept in mind although rare.

\section{KEYWORDS}

Herpes Zoster Ophthalmicus, Herpes Zoster Chorioretinopathy, Depigmented Chorioretinal Lesions, Occlusive Vasculitis.

HOW TO CITE THIS ARTICLE: Reddy LSH, Bhandary SV, Rao AK, et al. Unilateral multifocal chorioretinopathy a clue to herpes zoster ophthalmicus. J. Evolution Med. Dent. Sci. 2016;5(64):4596-4597, DOI: 10.14260/jemds/2016/1047

\section{CASE REPORT}

A 50-year-old female presented with irritation in her left eye. Her visual acuity in the left eye was 6/9 and N8 with correction. On examination, [RE] was within normal limits, [LE] showed decreased corneal sensations, dry eye, and normal anterior segment. Fundus examination revealed multiple depigmented chorioretinal lesions $1 / 2$ to 3 DD in size located in the posterior pole suggestive of chorioretinal atrophic patches (Figure 1). Detailed history and systemic examination revealed no other abnormalities. OCT of the lesions showed increased back scattering from choroidal layers (Figure 2). FFA showed early hyperfluorescence, which increased in intensity with no increase in size, which faded away in the late phase suggestive of window defect (Figure 3). Patient was started on tear supplements, reassured, and asked to come for follow up after three weeks. Patient came for review after two months with redness in the left eye. The left eye examination showed iridocyclitis and vision had dropped to $6 / 18$ and N14. During this visit on further questioning,

Financial or Other, Competing Interest: None.

Submission 30-06-2016, Peer Review 27-07-2016,

Acceptance 01-08-2016, Published 11-08-2016.

Corresponding Author:

Dr. L. Satya Hareesh Reddy,

Junior Resident,

Department of Ophthalmology,

Kasturba Medical College,

Manipal.

E-mail: harish48564@gmail.com

DOI: $10.14260 /$ jemds/2016/1047 patient revealed that she had lesions over the forehead and nose [Along the distribution of ophthalmic division of trigeminal nerve] one year ago. She also told us that following this she had recurrent redness in left eye, which resolved on its own. She was started on ointment acyclovir, guttae loteprednol, homatropine, and tear supplements. On follow up, the iridocyclitis had resolved and visual acuity was $6 / 12$, N8 in the left eye.

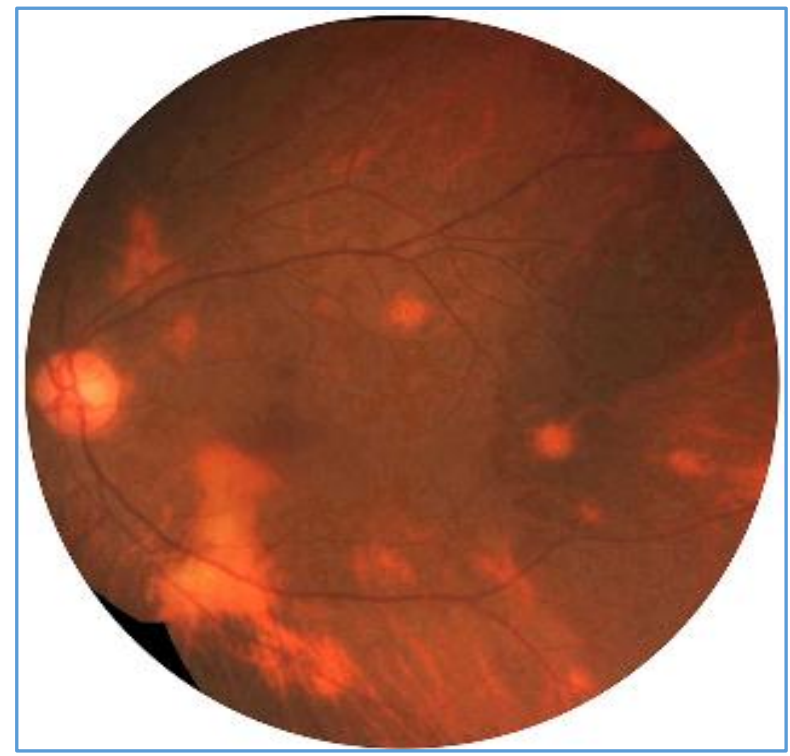

Fig. 1: Fundus of [LE] with Multiple, Depigmented Chorioretinal Lesions in the Posterior Pole Suggestive of Chorioretinal Atrophic Patches 


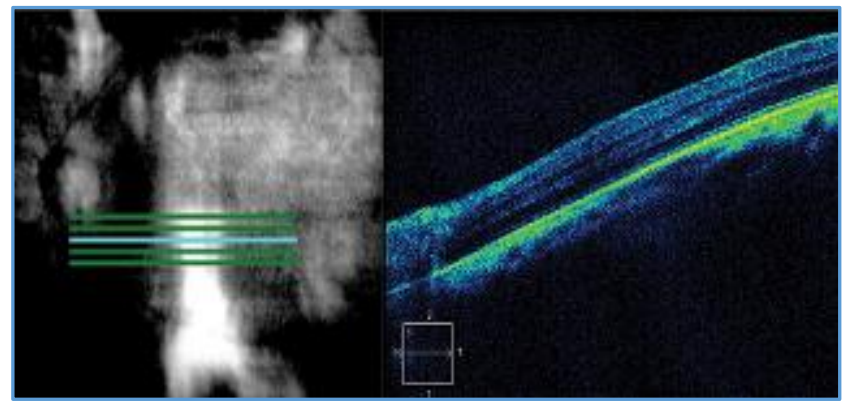

Fig. 2: OCT of the Lesions showing Increased Back Scattering from Choroidal Layers

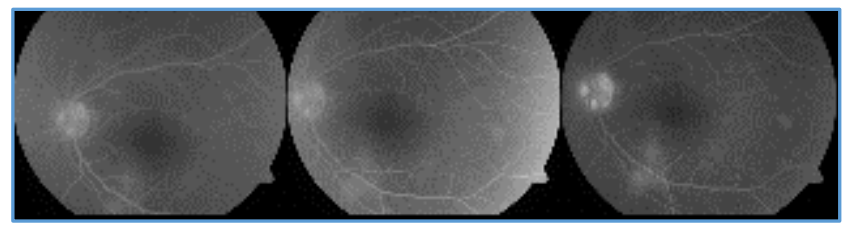

Fig. 3: FFA of [LE] Showing Early Hyperfluorescence, which Increased in Intensity with no Increase in Size, which Faded Away in the Late Phase Suggestive of Window Defect

\section{DISCUSSION}

HZCR is a rare and delayed complication of HZO as seen in our case and literature search revealed only 3 such cases in the past and the last case reported was in 1995.[1-4]

The pathophysiology includes direct viral infection of Retinal Pigment Epithelium (RPE) or secondary ischaemic occlusive vasculitis of the choriocapillaries. Direct lytic response or indirect $\mathrm{CD} 8+\mathrm{T}$-cell lysis is induced when virus adhere to adhesion molecules in RPE and choroidal vascular endothelium respectively. [5] The immune complex deposition in the wall of the affected vessel results in occlusive vasculitis.

Histopathological studies of eyes affected with HZO showed perineural and intraneural lymphocytic infiltration of the long posterior ciliary nerves. Perivasculitis or vasculitis was evident in vessels accompanying the involved nerves. Choroid showed granulomatous choroiditis with occlusive vasculitis of the short posterior ciliary arteries resulting in ischaemic atrophy of the outer retina.[6]

A spectrum of chorioretinal changes associated with herpes zoster infection have been described. T.V. Roberts et al in the year 1995 reported 2 cases of depigmented lesions at the level of choriocapillaries/RPE suggestive of chorioretinal atrophy following an attack of herpes zoster ophthalmicus.[4] R. J. Marsh and Cooper had reported one case of retinal pigment epithelium degeneration.[1] Amano and associates described three patients with many punched out oval areas of choroidal atrophy scattered around the mid periphery with scanty choroidal vessels and no pigmentary changes in the lesions.[7] Bloom and Snady-McCoy described a patient with 'multifocal choroiditis' that clinically resembled birdshot retinopathy ${ }^{[8]}$ But, Womack and Liesegang who reviewed 86 patients with HZO found none with retina involvement. ${ }^{[9]}$ In present report, in addition to the fundus picture, we have described the OCT and FFA features too. This can help ophthalmologists to know and suspect this condition.

Contralateral hemiplegia following HZO has pathogenesis similar to that of HZCR.[10] Studies found few patients with segmental cerebral arteritis on angiography[11] and others with normal carotid angiography, but occlusive granulomatous angiitis of small vessels. Our patient did not have hemiplegia.

The similar duration [Delayed] in development of HZCR and hemiplegia following HZO and the histopathological findings of granulomatous angiitis in both cerebral and choroidal vessels ${ }^{[6,9]}$ supports the assumption that occlusive choroidal vasculitis is the underlying mechanism in HZCR.

\section{OUTCOME}

The choroidal lesions remained the same and did not cause any visual impairment, however, patient had recurrent anterior uveitis, which was treated with topical steroids.

\section{CONCLUSIONS}

Unilateral, inactive, self-limiting depigmented chorioretinitis patches without foveal involvement or retinal detachment in an asymptomatic patient should raise the suspicion of past history of HZO although rare.

Awareness of such condition and its association avoids unnecessary investigations.

\section{LIST OF ABBREVIATIONS}

HZO - Herpes Zoster Ophthalmicus.

HZCR - Herpes Zoster Chorioretinopathy.

\section{REFERENCES}

1. Marsh RJ, Cooper M. Ophthalmic herpes zoster. Eye 1993;7(3):350-70.

2. Hedges TR, Albert DM. The progression of the ocular abnormalities of herpes zoster: histopathologic observations of nine cases. Ophthalmology 1982;89(2):165-77.

3. Karbassi M, Raizman MB, Schuman JS. Herpes zoster ophthalmicus. Survey of Ophthalmology 1992;36(6):395410.

4. Roberts TV, Francis IC, Kappagoda MB, et al. Herpes zoster chorioretinopathy. Eye 1995;9(5):594-8.

5. Forrester JV. Uveitis: pathogenesis. Lancet 1991;338(8781):1498-501.

6. Naumann G, Donald J, Gass M, et al. Histopathology of herpes zoster ophthalmicus. American Journal of Ophthalmology 1968;65(4):533-41.

7. Amano $Y$, Ohashi $Y$, Haruta $Y$, et al. A new fundus finding in patients with zoster ophthalmicus. American Journal of Ophthalmology 1986;102(4):532-3.

8. Bloom SM, Snady-McCoy L. Multifocal choroiditis uveitis occurring after herpes zoster ophthalmicus. American Journal of Ophthalmology 1989;108(6):733-5.

9. Womack LW, Liesegang TJ. Complications of herpes zoster ophthalmicus. Archives of Ophthalmology 1983;101(1):42-5.

10. Hilt DC, Buchholz D, Krumholz A, et al. Herpes zoster ophthalmicus and delayed contralateral hemiparesis caused by cerebral angiitis: diagnosis and management approaches. Annals of Neurology 1983;14(5):543-53.

11. MacKenzie RA, Forbes GS, Karnes WE. Angiographic findings in herpes zoster arteritis. Annals of Neurology 1981;10(5):458-64. 